\title{
Jump Dynamics And Volatility Components For OECD Stock Returns
}

\author{
Khaled Guesmi, Ph.D., IPAG Business School, IPAG Lab and Economix, Paris West University, France \\ Farhan Akbar, Ph.D., Paris 1 University, France \\ Irfan A. Kazi, Ph.D., Economix, Paris West University, France \\ Walid Chkili, Ph.D., Faculty of Management and Economic Sciences of Tunis, Tunisia
}

\begin{abstract}
The paper applies Markov Regime Switching Model (MRSM) to investigate the volatility behaviour of twelve OECD stock markets (U.S.A, France, Ireland, Netherlands, Spain, Denmark, Norway, Sweden, Switzerland, UK, Australia and Japan) for the period 2004-2010. The results highlight two different regimes: the first regime consist of low mean high volatility whereas the second regime is categorized by high mean low volatility. We conclude that the periods of high volatility are generally synchronous to several economic and/or political events in all the developed markets during the period under investigation.
\end{abstract}

Keywords: Dynamic Conditional Correlations; Markov Regime Switching; Conditional Volatility

\section{INTRODUCTION}

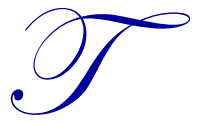

he subject of volatility dynamics has always been the focus of many researchers and practitioners in the field of economics and finance with the objective to achieve economic stability, higher rates of return for investors by portfolio diversification, optimization, and pricing of the securities. This subject attracted even more attention of the financial community due to a stream of crisis in the last few decades. The stock market crash of 1987(also known as Black Monday referring to Monday 19, October 1987) was an international phenomenon. The crash started in Hong Kong and moved with the time zone sweeping every market with it and reaching Australia and New Zealand on Tuesday and rightly called this phenomenon as Black Tuesday in these two countries. At the end of October 1987, stock markets around the world such as in Hong Kong, Australia, Spain, United Kingdom, United States, and Canada had fallen by $45.5 \%, 41.8 \%, 31 \%, 26.45 \%, 22.68 \%$, and $22.5 \%$ respectively. New Zealand had suffered the most, where the market declined by about $60 \%$ and took it several years to recover. It is of interest to observe that Japan during this drama suffered a crash but not a panic like situation as seen in the case of USA, mainly due to a strong and consistent institutional regulatory structure. Hamao and al. (1991) examine equity markets around the 1987 and find evidence of significant price-volatility spill over from New York to London and Tokyo, and from London to Tokyo. In December 1994, Mexico faced economic crisis which was the first of a new style of crisis (Edwards \& Naim, 1998). The impact of this financial disaster was readily observed in Latin American countries and was named as Tequila Effect. A similar kind of crisis emerged in July 1997 in Thailand, which was far more severe and engulfed far more countries than its' predecessor. Due to its' severity and contagion it became commonly known as Asian Crisis. The emergence of East Asian currency crisis in 1997 raised doubt about the lessons learned from Mexico by national and international policy makers, and economic analysts (Edwards \& Naim, 1998). Then again in 2007, the world witnessed the worst crisis in history after the Great Depression of 1929. The crisis emerged in U.S.A due to a complicated interplay of different variables. Commonly cited causes are the lower interest rates, abundance of mortgage loans, weak or no controls at institutional and authoritative levels, and the use of securitization. In all the cases mentioned above we observe lower rates of return, higher volatility, and its' propagation to other stock markets around the world during the periods of turbulence.

In this research paper, we study the behaviour of volatility in twelve Organization of Economic Cooperation and Development (OECD) member countries. Our main focus remains on two most important issues. First, we estimate the conditional correlations between the stock markets of US (NASDAQ 100) and the rest of 
sixteen OECD countries for the period 2004 to 2010. Dynamic conditional correlations provide an important insight into the Global Financial Crisis 2007-2009 and its' impact on the rest of sixteen countries. To achieve this task, we use Dynamic Conditional Correlation (DCC) GARCH Model of Engel (2002) and Engle and Sheppard (2001). Second, we apply Markov Regime Switching (MRS) GARCH model developed by Hamilton and Susmel (1994), Cai (1994) and Edwards and Susmel (2003) to study volatility of twelve OECD member countries under different regimes and under crisis period. The main attraction of using MRS GARCH Model lies in its' ability to calculate changing variance under different regimes.

The rest of the paper is organized as follows: In section 2, we present a detailed literature review about the DCC GARCH and MRS GARCH Model. Section 3 focuses on the research methodology applied in the research. Section 4 presents the empirical results. Finally, section 5 provides conclusions.

\section{LITERATURE REVIEW}

In literature we find many volatility models, but among all those models GARCH (Generalized Autoregressive Conditional Heteroskedasticity) model proposed by Bollersleve (1986) earned the greatest success, which is a generalization of the seminal work on ARCH by Engle (1982). We also find GARCH in different flavours incorporating various time series properties such as asymmetries (GJR GARCH), long memory (LMGARCH), structural breaks (Markov Regime Switching GARCH), and time varying volatility (DCC GARCH). Our focus remains on the DCC GARCH and Markov Regime Switching GARCH models.

Markov Switching Models were first analyzed by Lindgren (1978) and Baum and al. (1980) without incorporating any autoregressive elements. Poritz (1982), Juang and al. (1985), and Rabiner (1989) applied Morkov Switching Models with autoregressive element in speech recognition and called the process as "Hidden Markov Models". Goldfeld and Quandt (1973) were the first to introduce Markov Switching Regression in Econometrics. To account for the possible presence of structural breaks, Cai (1994) and Hamilton and Susmel (1994) applied the idea of regime-switching parameters by Hamilton $(1988,1989,1990)$ into an ARCH specification (Juri, 2005). Gray (1996) was the first to introduce Markov Regime Switching GARCH and applied his model on weekly data of U.S. Treasury bill rates from January 1979 to April 1994. He also mentioned how Exponential GARCH could be incorporated to estimate Markov Regime Switching EGARCH. This innovation led to a flood of research applications. Klaassen (2002) modified Gray's model by adopting the conditional expectation of the lagged conditional variance with a broader information set. This model is superior to the previous as it allows for multi-step-ahead forecast as in standard GARCH and offers a higher flexibility in capturing the persistence of volatility shocks. Haas and al. (2004) developed a new MRS GARCH model by extending to multi-regime switching, analytically tractability, and provide richer dynamics for the process involved.

In literature, we also observe an abundance of the use of MRS GARCH and its' variations. For example, Fong and Koh (2002) applied Markov Regime Switching EGARCH on Hong Kong stock market over a long sample period and found strong evidence of regime shifts in conditional volatility as well as significant volatility asymmetry in high volatility periods. Maheu and McCurdy (2004) apply MRS with Auto-regression to study the volatility in U.S stock market and find strong evidence of: high mean and low volatility, and low mean and high volatility under two regimes. Edwards and Susmel (2003) study the interest rate volatility in emerging markets by applying a modified version of MRS with ARCH and find evidence of regime shifts. Kanas (2005) applied Markov Switching with vector auto-regression (MS-VAR) to study the relationship between Mexican currency and six emerging stock markets. Hondroyiannis and Papapetrou (2006) study the dynamic relationship between real stock returns and expected and unexpected inflation of Greece utilizing a MS-VAR. They find no evidence of relation between real stock returns and expected and unexpected inflation. Moore and Wang (2007) investigate the volatility in stock markets for the new European Union member states by applying Markov Regime Switching Model (MRSM) and reveal that there is a tendency in emerging stock markets to move from high volatility regime in the earlier period of transition into the lower volatility regime as they move into the EU. Brunetti et al. (2008) analyze exchange rate turmoil in South Asia with a Time Varying Markov Switching GARCH model and find that the real effective exchange rates, money supply relative to reserves, stock index returns, and bank stock index returns and the volatility contain valuable information for identifying turbulence and ordinary periods. Wang and Theobald (2008) apply MS model to study the behaviour in the return-generating processes of six East Asian emerging stock markets. 
They find strong evidence of more than one regime in each stock market under study and mixed evidence regarding the impact of financial liberalization on return volatility. Cologni and Manera (2009) investigate the impact of oil price shocks on economic growth rates of a subset of developed countries (G7) by applying alternative switching models. Their empirical evidence supports the notion of lesser/ decreasing role of oil price shocks on the business cycles of G7 member countries. Mandilaras and Bird (2010) apply MS Vector Autoregression to distinguish between crisis and non-crisis observation endogenously. They favour the use of MS-VAR to other methodologies as this model performs better in identifying the 11 realignments of the exchange rate mechanism.

Our paper contributes to the research on the use of MS-GARCH models on two fronts. First, we use daily data contrary to the weekly data found in literature. Second, we do not find any other research which has focused on the OECD member countries at such as large scale.

\section{METHODOLOGY}

\section{Modeling Dynamic Conditional Correlation}

In this research, we apply the time-varying correlation coefficients estimated from a multi-variate DCC-GARCH model intruded by Engle (2002) to measure the co movements between US markets and OCDE stock market.

By allowing conditional correlations to vary over time, his specification is viewed as a generalization of the Constant Conditional Correlation model (CCC model, Bollerslev (1990)). To illustrate the dynamic conditional correlation model for our purposes, let $x_{t}$ be a $(12 \times 1)$ vector containing the return, volume, and implied volatility series in a conditional mean equation as:

$x_{\mathrm{t}}=\mu_{\mathrm{t}}+\varepsilon_{\mathrm{t}}$

where $\mu_{\mathbf{t}}=E\left[x_{\mathbf{t}} \| \Pi_{\mathbf{t}-\mathbf{1}}\right]$ is the conditional expectation of $x_{\mathbf{t}}$ given the past information $\Pi_{\mathbf{t}-\mathbf{1}}$, and $\varepsilon_{\mathbf{t}}$ is a vector of errors in the autoregression $\operatorname{AR}(1)$, are assumed to be conditional multivariate normally distributed, with means of zero and variance-covariance matrix $H_{\mathbf{t}} \equiv\left\{h_{i j}\right\}$. Under the assumption that the return, volume and implied volatility series $x_{t}$ are determined by the information set available at time $\mathrm{t}-1$, the model may be estimated using maximum likelihood methods, subject to the requirement that the conditional covariance matrix, $H_{\mathbf{t}}$, be positive definite for all values of $\boldsymbol{\varepsilon}_{\mathfrak{t}}$ in the sample. We also assume that $\mu_{\mathrm{t}}$ has the following formation as:

$\mu_{i, t}=\Phi_{0}+\Phi_{1} x_{i, t-1}, \forall \mathrm{i}$

$\Phi_{1}$ measures the ARCH effect in data series. In the traditional multivariate GARCH framework, the conditional variance-covariance matrix can be written as:

$H_{t}=G_{t} R_{t} G_{t} \quad$ where $G_{t}=\operatorname{diag}\left\{\sqrt{h_{i t}}\right\}$

$h_{i t}$ is the estimated conditional variance from the individual standard univariate $\operatorname{GARCH}(1,1)$ models in the following manner,

$h_{i t}=\omega_{i}+\alpha_{i} \varepsilon_{i, t-1}^{2}+\beta_{i} h_{i, t-1} \quad \forall i$ 
$R_{t}$ is the time-varying conditional correlation coefficient matrix. According to the specification in equation (4), each market's variance is modeled as a function of the constant, the square of last period's own residuals $\varepsilon_{i, t-1}^{2}$, and its lagged conditional variance $h_{i, t-1}$. After the above basic construction, the dynamic correlation coefficient matrix of the DCC model can be denoted further:

$$
\begin{gathered}
R_{t}=\left[\operatorname{diag}\left(Q_{t}\right)\right]^{\frac{1}{2}} Q_{t}\left[\operatorname{diag}\left(Q_{t}\right)\right]^{-\frac{1}{2}} \\
Q_{t}=\left(q_{i j, t}\right) \\
{\left[\operatorname{diag}\left(Q_{t}\right)\right]^{-\frac{1}{2}}=\operatorname{diag}\left(\frac{1}{\sqrt{q_{11, t}}}, \frac{1}{\sqrt{q_{22, t}}}, \ldots \frac{1}{\sqrt{q_{12,12, t}}}\right)}
\end{gathered}
$$

In order to standardize the residual error term, Engle sets $w_{\mathbf{t}}=G_{t}^{-1} \varepsilon_{t}$ where $G_{t}$ is a (12×12) diagonal matrix of conditional standard deviations. $z_{t}$ is the standardized residuals vector with mean zero and variance one. Engle also suggests estimating the following time-varying correlation process

$$
\rho_{i j, t}=\frac{q_{i j, t}}{\sqrt{q_{i i, t} q_{j j, t}}}
$$

where

$$
q_{i j, t}=\bar{\rho}_{i j}+a\left(z_{i, t-1} z_{j, t-1}-\bar{\rho}_{i j}\right)+b\left(q_{i j, t-1}-\bar{\rho}_{i j}\right)=(1-a-b) \bar{\rho}_{i j}+a z_{i, t-1} z_{j, t-1}+b q_{i j, t-1}
$$

the time-varying correlation coefficients in DCC-GARCH model can be divided into two parts. The first part indicated in the right hand side of equation (6) $\bar{\rho}_{i j}$ represents the unconditional expectation of the cross product $z_{i t} z_{j t}$, i.e. the unconditional correlation coefficient. The second part indicated on the right hand side of equation (6) $a z_{i, t-1} z_{j, t-1}+b q_{i j, t-1}$ shows the conditional time-varying covariance. Compare the traditional GARCH $(1,1)$ model in equation (4) with DCC-GARCH model in equation (6), we can show that the DCC-GARCH model standardized the residual error term into standard normal distribution, and the constant term in DCC-GARCH model represents the unconditional correlation between error term, other than the CCC constant correlation setting (Bollerslev (1990).

Additionally, DCC-GARCH model contributes to the parameters estimation process in two parts. The first is that the conditional correlation defined in the DCC-GARCH can be modeled individually as a GARCH process, and the second is that the unconditional expectations $\bar{\rho}_{i j}$ of the residual errors can be estimated separately by historical data. 


\section{Regime-Switching GARCH}

Let $r_{i t}$ be the return at time $\mathrm{t}$, modelled in terms of a constant and a disturbance term such that:

$r_{t}=\mu\left(S_{t}\right)+\varepsilon_{t}$

$\varepsilon_{t} \rightarrow \varepsilon_{t} \sqrt{h_{t}\left(S_{t}\right)}$

$h_{t}\left(S_{t}\right)=\alpha_{0}\left(S_{t}\right)+\alpha_{1} \varepsilon_{t-1}^{2}+\beta_{1}\left(S_{t}\right) h_{t-1}$

where $S_{t}=0$ or $1 \mu\left(S_{t}\right)$ and $h_{t}\left(S_{t}\right)$ are the conditional mean and conditional variances respectively. Both are allowed to switch between two regimes. To ensure positivity of conditional variance in each regime, necessary conditions are similar to the necessary conditions in uni-regime $\operatorname{GARCH}(1,1)$ model. The unobserved regime variable $S_{t}$ is governed by a first order Markov Chain with constant transition probabilities given by

$\operatorname{Pr}\left(S_{t}=0 / S_{t-1}=0\right)=P_{00}$

$\operatorname{Pr}\left(S_{t}=1 / S_{t-1}=1\right)=P_{11}$

$\operatorname{Pr}\left(S_{t}=0 / S_{t-1}=1\right)=P_{10}=1-P_{11}$

$\operatorname{Pr}\left(S_{t}=1 / S_{t-1}=0\right)=P_{01}=1-P_{00}$

In matrix notation,

$P=\left[\begin{array}{cc}P_{00} & 1-P_{11} \\ 1-P_{00} & P_{11}\end{array}\right]$

Then, conditional distribution of return series $r_{t}$ becomes a mixture of distribution model in which mixing variable is ex-ante probability $\operatorname{Pr}\left(S_{t}=i / \pi_{t-1}\right)$ denoted by $P_{i t}$,

$r_{t} / \pi_{t-1}=\left\{\begin{array}{l}f\left(r_{t} / S_{t}=0, \pi_{t-1}\right) \text { with probability } p_{0 t} \\ f\left(r_{t} / S_{t}=1, \pi_{t-1}\right) \text { with probability } p_{1 t}=1-p_{0 t}\end{array}\right.$

where $f\left(r_{t} / S_{t}=1, \pi_{t-1}\right)$ denotes one of the assumed conditional distributions for errors: Normal, Student-t or GED. $\pi_{t-1}$ denotes the information at time t-1. $p_{0 t}$ is the ex-ante probability of being in regime 0 . The log-likelihood function for SW-GARCH model can be written as 


$$
\begin{aligned}
& L=\sum_{t=1}^{T} \ln \left[\sum_{S_{t}=1}^{2} f\left(r_{t} / S_{t}=1, \pi_{t-1}\right) \operatorname{Pr}\left(S_{t} / \pi_{t-1}\right)\right]= \\
& \sum_{t=1}^{T} \ln \left[f\left(r_{t} / S_{t}=0, \pi_{t-1}\right) p_{0 t}+f\left(r_{t} / S_{t}=1, \pi_{t-1}\right) p_{1 t}\right]
\end{aligned}
$$

The $\operatorname{Pr}\left(S_{t} / \pi_{t-1}\right)$ is called regime probability, is the probability that the process is in regime $i$ at time $t$ based on the all information up to time $\mathrm{t}-1$.

\section{EMPIRICAL RESULTS}

\section{Descriptive Statistics}

Table 1 presents descriptive statistics for the stock market returns under study. The Norwegian market displays the highest average return $(0.05 \%)$, followed by markets in Sweden $(0.03 \%)$ and Denmark $(0.03 \%)$, whereas the Irish market has a negative average return $(-0.03 \%)$. We observe Norway $(1.7 \%)$ and Ireland $(1.69 \%)$ markets to be highly volatile, while Australian (1.1\%) market is the least volatile. The coefficients of asymmetry (skewness) are negative for all countries except the Czech Republic, Spain and France. They are significantly different from zero for almost all stock markets, indicating the presence of asymmetry and the potential of non-linearity in the process generating the returns. In addition, all the return series are characterized by a coefficient of kurtosis statistically significant and greater than 3 , and therefore the distribution tails are thicker than the normal distribution. The results of Jarque-Bera test confirm the rejection of normality.

Table 2 presents unconditional correlations between stock market returns. The highest correlation is between the French market and the Netherlands market (0.94) whereas a negative correlation exists between the markets of Spain and Ireland (-0.05).

\section{Dynamic Correlation}

The application of DCC-GARCH $(1,1)$ model facilitates to study the relationship of interdependence and transmission of shocks between the markets and in our case we study the interdependence and transmission of shocks between one of the OECD stock market and the US stock market. In Figure 2 we illustrate the conditional correlation between one of the OECD stock markets and the US stock market and in figure 3 we present the time varying volatility of each stock index. It is evident that the correlation coefficients vary with respect to time and they are found to be positive for all markets. The graphs show that the correlations between one of the OECD stock market and USA stock market rose remarkably during the financial crisis of 2007. In Table 3 we observe the highest dynamic correlation of 0.503 on average between U.S and Netherlands stock markets. The correlation between these markets reached to a level of 0.628 during the crisis period and a change of 52\% in correlation between the highest correlation (during the crisis period) and the lowest correlation (tranquil period). The second highest dynamic correlation of 0.496 on average is observed between the U.S stock market and the French stock market, again we see that this correlation reached at its' peak of 0.607 during the crisis period and a change of $47 \%$ in dynamic correlation is observed between the highest correlation (during the crisis period) and the lowest correlation (tranquil period). In our study we find four dynamic correlations quite interesting, the correlations between US and Australia, US and Ireland, US and Japan, and at last the correlation between US and Spain. The correlation changed by $852 \%$ between U.S stock market and the Australian stock market. The dynamic correlation between these markets reached the top at 0.201941 during the crisis period and reached at its' lowest point of -0.0269 during the tranquil period. We observe $336 \%, 254 \%$, and $158 \%$ change in the dynamic correlation between the pairs of US-Ireland, US-Japan, and US-Spain respectively. For all these four cases discussed, the correlations were around negative during the tranquil period and became positive during the crisis. Further we observe that the shocks which affect the U.S stock market also significantly affect other OECD stock markets. This proves that there is certain level of integration among the OECD stock markets under study, which is 
specifically very true for the European countries. Our results are consistent with that of Forbes and Rigobon (2002) who stressed that the increased correlation during times of crises is due to increased volatility in global stock markets. Similarly, Longin and Solnik (1995) emphasized the instability of the relationship of correlation between international stock markets, and observe that the volatility and correlations of stock markets rose significantly after the 1987 stock market crash. The positive relationship between volatility and correlation was also confirmed by King et al (1994), Ramchand and Susmel (1998) and Morana and Belttratti (2002).

\section{Identification of Regime Change}

Several authors such as Wang and Theobald (2008) stressed that the identification of regime change is difficult as the search for the number of regimes cannot be observed through the use of simple Wald ratio and the test of likelihood ratio.

To resolve this problem, we have applied the likely hood ratio test developed by Garcia and Perron (1996) to verify the existence of regime change for each market under study. However, we test the null hypothesis of no regime change for the stock market returns represented by the GARCH $(1,1)$ model with a single regime against the Markov Regime Switching (MS-GARCH $(1,1)$ ) specification, which implies the existence of more than one regime for each stock market under study. We start by determining the number of delays with the help of autoregressive model by applying the Akaike Information Criteria (1974) and of Hannan et Quinn (1977). The LR test is defined as $L R=2\left|\ln L_{M S-G A R C H}-\ln L_{G A R C H}\right|$ and the critical value for model with two regime shifts is tabulated by Garcia et Perron (1996) and Garcia (1998) based on the study of Davies (1987). Table 4 shows that the LR test statistics are higher than the critical value for all markets. Hence we can reject the null hypothesis of no regime change at a significance level of $1 \%$. However, it is clear that stock market returns of the OECD are better described by a Markov Switching GARCH model compared to a GARCH $(1,1)$ with a single regime.

Table 5 highlights that the GARCH model is capable of capturing the volatility clustering and the estimated coefficients are statistically different from zero which means that the conditional variance depends upon the past observations and past shocks. Thus, for all OECD markets the model is stationary since $\beta<1$.

The results of the estimation of MS-GARCH model allow us to identify two types of regimes: the first regime with a negative average return with a very high volatility for all markets under study as evident from figure 4 and 5. There is also a second regime with lower volatility and positive average returns. Referring to Maheu and McCurdy (2000), regime 1 is considered a "bear market", while regime 2 is considered as "bull market". The average returns during regime 1 ranges from $-0.647 \%$ for Norway to -0.307 for the UK. While the average return is positive for all markets for regime 2 except U.S. The average ranges between $-0.983 \%$ for U.S Japan to $0.244 \%$ for Norway. MS-GARCH model also shows that the probability that a day of high volatility will be followed by another day of high volatility. The probability of transition from regime1 to regime 1 is 0.909 for the UK followed by France (0.905), while the SWE has the lowest probability. The probability that a day of low volatility will be followed by another day of low volatility varies around 0.987 for Japan. Regime 1 continues for an average of 3.12 days for SWE and is the lowest average among the markets under study. The highest average is that of France which has a value of 10.50 days. In addition, regime 2 is much more persistent than regime 1 for all markets. The average ranges from 16.39 days for Sweden to 76.92 days for Japan. 


\section{CONCLUSION}

In this paper, we study the volatility of 12 OECD stock markets. We employ two empirical approaches. The first is based on the dynamic conditional correlation model to test the dynamic relationship between OCDE and the U.S. stock market. The second model uses the Markov regime shifts in order to study the behaviour of twelve OECD stock markets during the financial crises (2007-2010). We prove that most of the OECD stock markets are closely interlinked to the U.S. highlighting some contagion between markets. However, the relationship of correlation increased significantly during the periods of crises that have affected these markets.

\section{AUTHOR INFORMATION}

Khaled Guesmi, Ph.D., IPAG Business School, IPAG Lab and Economix, Paris West University Nanterre La Defense, E-mail: Khaled.guesmi@ipag.fr (Corresponding author)

Farhan Akbar, Ph.D., CES (UMR CNRS 8174), Université Paris 1 Panthéon-Sorbonne, France, E-mail: farhan_a_kazi@yahoo.com

Irfan A. Kazi, Economix, Ph.D., (UMR CNRS 7235), Université Paris Ouest Nanterre La Défense, France, E-mail: irfan.a.kazi@gmail.com

Walid Chkili, Ph.D., IFGT, Faculty of Management and Economic sciences of Tunis, Tunisia, E-mail: walid.chkili@fsegt.rnu.tn

\section{BIBLIOGRAPHY}

1. Baum, Leonard E., Ted Petrie, George Soules, and Norman Weiss. (1980). A Maximization Technique Occurring in the Statistical Analysis of Probabilistic Functions of Markov Chains. Annals of Mathematical Statistics 41, 164-171.

2. Bogle, J. C. (2008). Black Monday and Black Swans. Financial Analysts Journal, 64 (2).

3. Bollersleve, T. (1986). Generalized Autoregressive Conditional Heteroskedasticity. Journal of Econometrics, 31, 307-327

4. Brunetti, C., Scotti, C., Mariano, R. S., \& Tan, A. H. (2008). Markov switching GARCH models of currency turmoil in Southeast Asia. Emerging Markets Review, 9 (2), 104-128.

5. Cai, J. (1994). A Markov model of switching regime ARCH. Journal of Business and Economic Statistics 12, 309-316.

6. Cologni, A., \& Manera, M. (2009). The asymmetric effects of oil shocks on output growth: A Markov-Switching analysis for the G-7 countries. Economic Modelling , 26 (1), 1-29.

7. Edwards, S., \& Naim, M. (1998). Mexico 1994: Anatomy of an Emerging-Market Crash. Carnegie Endowment for International Peace.

8. Edwards, S., Susmel, R. (2003). Volatility dependence and contagion in emerging equity markets. Journal of Development Economics, 66, 505-532.

9. Engle, R. (2002). Dynamic conditional correlation: A simple class of multivariate generalized autoregressive conditional heteroskedasticity models. Journal of Business and Economic Statistics, 20(3) 339-350.

10. Engle, R. (1982). Autoregressive conditional heteroscedasticity with estimates of the variance of U.K. inflation. Econometrica, 50, 987-1008.

11. Engle, R. F., \& Granger, C. W. J. (1987). Cointegration and error correction: representation, estimation, and testing. Econometrica 55, 251-276.

12. Engle, R.F. and K. Sheppard. (2001). Theoretical and Empirical Properties of Dynamic Conditional Correlation Multivariate GARCH. NBER Working Paper, no. 8554 (2001).

13. Fong, W. M., \& Koh, S. K. (2002). The Political Economy of Volatility Dynamics in the Hong Kong Stock Market. Asia-Pacific Financial Markets, 19, 259-282. 
14. Goldfeld, Stephen M., and Richard E. Quandt. (1973). A Markov Model for Switching Regressions. Journal of Econometrics 1, 3-16.

15. Gray, Stephen F. (1996). Modeling the Conditional Distribution of Interest Rates as a Regime-Switching Process. Journal of Financial Economics 42, 27-62.

16. Haas,M., S. Mittnik, and M. S. Palolella. (2004). A New Approach to Markov-Switching GARCH Models. Journal of Financial Econometrics 2(4), 493-530.

17. Hamilton, James D. (1988). Rational-Expectations Econometric Analysis of Changes in Regime: An Investigation of the Term Structure of Interest Rates. Journal of Economic Dynamics and Control 12, 385-423.

18. Hamilton, James D. (1989). A New Approach to the Economic Analysis of Nonstationary Time Series and the Business Cycle. Econometrica 57, 357-384.

19. Hamilton, James D. (1994), Time Series Analysis, Princeton, NJ: Princeton University Press.

20. Hamilton, James D. (1996). Specification Testing in Markov-Switching Time-Series Models. Journal of Econometrics 70, 127-157.

21. Hamilton, James D. (2005). What's Real About the Business Cycle?. Federal Reserve Bank of St. Louis Review.

22. Hamilton, James D., and Gang Lin (1996). Stock Market Volatility and the Business Cycle. Journal of Applied Econometrics 11, 573-593.

23. Hamilton, James D., and Gabriel Perez-Quiros. (1996). What Do the Leading Indicators Lead?. Journal of Business 69, 27-49.

24. Hamilton J.D., Susmel, R. (1994). Autoregressive conditional hetroscedasticity and changes in regime. Journal of Econometrics 70, 127-157.

25. Hamao, Y.R., R.W. Masulis and V.K. Ng. (1991). The Effect of the 1987 Stock Crash on International Financial Integration. In W.T. Ziemba, W. Bailey and Y.R. Hamao (eds.), Japanese Financial Market Research, Elsevier, 483-502.

26. Hondroyiannis, G., \& Papapetrou, E. (2006). Stock returns and inflation in Greece: A Markov switching approach. Review of Financial Economics, 15 (1), 76-94.

27. Juang, Biing-Hwang, and Lawrence R. Rabiner. (1985). Mixture Autoregressive Hidden Markov Models for Speech Signals. IEEE Transactions on Acoustics, Speech, and Signal Processing ASSP-30, 1404-1413.

28. Juri, M. (2005). Forecasting Stock Market Volatility with Regime-Switching GARCH Models. Studies in Nonlinear Dynamics \& Econometrics, 9 (4).

29. Kanas, A.(2005). Regime linkages between the Mexican currency market and emerging equity markets. Economic Modelling 22, pp. 109-125

30. Klaassen, F. (2002). Improving GARCH Volatility Forecasts with Regime-Switching GARCH. Empirical Economics, 27, 363-394.

31. Lindgren, G. (1978). Markov Regime Models for Mixed Distributions and Switching Regressions. Scandinavian Journal of Statistics, 5, 81-91.

32. Maheu, J.M. and T.H. McCurdy (2000). Identifying bull and bear markets in stock returns. Journal of Business and Economic Statistics, 18, 100-112.

33. Maheu, John M. \& Thomas H. McCurdy (2004). News Arrival, Jump Dynamics, and Volatility Components for Individual Stock Returns. Journal of Finance, American Finance Association, vol. 59(2), pages 755-793, 04.

34. Mandilaras, A., \& Bird, G. (2010). A Markov switching analysis of contagion in the EMS. Journal of International Money and Finance, 29 (6), 1062-1075.

35. Moore, T., \& Wang P. (2007). Volatility in stock returns for new EU member states: Markov regime switching model. International Review of Financial Analysis, Volume 16( 3), 282-292.

36. Poritz, Alan B. (1982). Linear Predictive Hidden Markov Models and the Speech Signal. Acoustics, Speech and Signal Processing, IEEE Conference on ICASSP '82, vol. 7, 1291-1294.

37. Rabiner, Lawrence R. (1989). A Tutorial on Hidden Markov Models and Selected Applications in Speech Recognition. Proceedings of the IEEE 77, 257-286.

38. Wang, P., \& Theobald, M. (2008). Regime-switching volatility of six East Asian emerging markets. Research in International Business and Finance, 22 (3), 267-283. 
ANNEXURE

Table 1: Descriptive Statistics

\begin{tabular}{|c|c|c|c|c|c|c|}
\hline & R_USA & $R \_A U S$ & R_CHE & $R \_D N K$ & $R \_E S P$ & R_FRA \\
\hline Mean & 0.0001 & 0.0002 & 0.0001 & 0.0003 & 0.0002 & 0.0000 \\
\hline Standard Error & 0.0004 & 0.0003 & 0.0003 & 0.0003 & 0.0003 & 0.0003 \\
\hline Median & 0.0007 & 0.0005 & 0.0005 & 0.0008 & 0.0010 & 0.0004 \\
\hline Standard Deviation & 0.0149 & 0.0114 & 0.0118 & 0.0140 & 0.0144 & 0.0145 \\
\hline Sample Variance & 0.0002 & 0.0001 & 0.0001 & 0.0002 & 0.0002 & 0.0002 \\
\hline Kurtosis & 8.2311 & 6.2634 & 9.5858 & 7.8638 & 11.5756 & 9.0229 \\
\hline Skewness & -0.0707 & -0.6389 & 0.0415 & -0.3225 & 0.2004 & 0.1138 \\
\hline Range & 0.2296 & 0.1391 & 0.1890 & 0.2122 & 0.2342 & 0.2007 \\
\hline Minimum & -0.1111 & -0.0855 & -0.0811 & -0.1172 & -0.0968 & -0.0947 \\
\hline Maximum & 0.1185 & 0.0536 & 0.1079 & 0.0950 & 0.1374 & 0.1059 \\
\hline Count & 1746.0000 & 1746.0000 & 1746.0000 & 1746.0000 & 1746.0000 & 1746.0000 \\
\hline & R_GBR & $R \_I R L$ & $R \_J P N$ & $R \_N L D$ & $R \_N O R$ & $R \_S W E$ \\
\hline Mean & 0.0001 & -0.0003 & 0.0000 & 0.0000 & 0.0005 & 0.0003 \\
\hline Standard Error & 0.0003 & 0.0004 & 0.0004 & 0.0003 & 0.0004 & 0.0003 \\
\hline Median & 0.0004 & 0.0001 & 0.0000 & 0.0007 & 0.0015 & 0.0008 \\
\hline Standard Deviation & 0.0128 & 0.0169 & 0.0163 & 0.0145 & 0.0170 & 0.0141 \\
\hline Sample Variance & 0.0002 & 0.0003 & 0.0003 & 0.0002 & 0.0003 & 0.0002 \\
\hline Kurtosis & 9.6849 & 7.2729 & 10.2447 & 9.8165 & 5.6748 & 5.3235 \\
\hline Skewness & -0.1330 & -0.5875 & -0.2001 & -0.2115 & -0.7044 & -0.0059 \\
\hline Range & 0.1865 & 0.2370 & 0.2535 & 0.1962 & 0.1890 & 0.1601 \\
\hline Minimum & -0.0926 & -0.1396 & -0.1211 & -0.0959 & -0.0971 & -0.0738 \\
\hline Maximum & 0.0938 & 0.0973 & 0.1323 & 0.1003 & 0.0919 & 0.0863 \\
\hline Count & 1746.0000 & 1746.0000 & 1746.0000 & 1746.0000 & 1746.0000 & 1746.0000 \\
\hline
\end{tabular}

Table 2: Correlations

\begin{tabular}{|c|c|c|c|c|c|c|c|c|c|c|c|c|}
\hline & $R \_U S A$ & $R \_A U S$ & R_CHE & $R \_D N K$ & $R_{-} E S P$ & R_FRA & R_GBR & $R \_I R L$ & $R \_J P N$ & $R \_N L D$ & $R \_N O R$ & $R \_S W E$ \\
\hline R_USA & 1.0 & & & & & & & & & & & \\
\hline R_AUS & 0.0784 & 1.0 & & & & & & & & & & \\
\hline R_CHE & 0.4522 & 0.3820 & 1.0 & & & & & & & & & \\
\hline R_DNK & 0.3884 & 0.4297 & 0.7288 & 1.0 & & & & & & & & \\
\hline R_ESP & -0.0343 & 0.0428 & -0.0381 & -0.0255 & 1.0 & & & & & & & \\
\hline R_FRA & 0.5019 & 0.3692 & 0.8646 & 0.7606 & -0.0301 & 1.0 & & & & & & \\
\hline R_GBR & 0.4744 & 0.3758 & 0.8560 & 0.7563 & -0.0492 & 0.9275 & 1.0 & & & & & \\
\hline R_IRL & 0.0303 & -0.0046 & 0.0158 & 0.0253 & -0.0578 & 0.0092 & 0.0007 & 1.0 & & & & \\
\hline R_JPN & -0.0026 & 0.0268 & 0.0208 & 0.0334 & -0.0193 & 0.0224 & 0.0160 & 0.0138 & 1.0 & & & \\
\hline R_NLD & 0.5110 & 0.3722 & 0.8386 & 0.7595 & -0.0528 & 0.9439 & 0.9077 & 0.0124 & 0.0143 & 1.0 & & \\
\hline R_NOR & 0.3528 & 0.4015 & 0.6446 & 0.7079 & -0.0192 & 0.7242 & 0.7380 & -0.0105 & -0.009 & 0.7398 & 1.0 & \\
\hline R_SWE & 0.4602 & 0.3687 & 0.7835 & 0.7687 & -0.0366 & 0.8651 & 0.8350 & 0.0199 & 0.026 & 0.8504 & 0.74 & 1.0 \\
\hline
\end{tabular}

Table 3: Country wise Average, Highest and Lowest Dynamic Correlations between USA and Rest of the OECD Countries

\begin{tabular}{|c|c|c|c|c|c|}
\hline \multicolumn{2}{|c|}{ AVERAGE DCC } & \multicolumn{2}{|c|}{ HIGHEST DCC } & \multicolumn{2}{|c|}{ LOWEST DCC } \\
\hline USA_NLD_CORR & 0.504 & USA_NLD_CORR & 0.628 & USA_NLD_CORR & 0.415 \\
\hline USA_FRA_CORR & 0.497 & USA_FRA_CORR & 0.608 & USA_FRA_CORR & 0.413 \\
\hline USA_GBR_CORR & 0.469 & USA_CHE_CORR & 0.585 & USA_CHE_CORR & 0.371 \\
\hline USA_SWE_CORR & 0.452 & USA_GBR_CORR & 0.578 & USA_GBR_CORR & 0.370 \\
\hline USA_CHE_CORR & 0.445 & USA_SWE_CORR & 0.576 & USA_SWE_CORR & 0.358 \\
\hline USA_DNK_CORR & 0.380 & USA_NOR_CORR & 0.521 & USA_DNK_CORR & 0.278 \\
\hline USA_NOR_CORR & 0.339 & USA_DNK_CORR & 0.520 & $U S A \_N O R \_C O R R$ & 0.204 \\
\hline USA_AUS_CORR & 0.080 & USA_AUS_CORR & 0.202 & USA_AUS_CORR & -0.027 \\
\hline USA_IRL_CORR & 0.030 & USA_IRL_CORR & 0.136 & USA_IRL_CORR & -0.058 \\
\hline$U S A \_J P N \_C O R R$ & -0.004 & USA_JPN_CORR & 0.121 & USA_JPN_CORR & -0.079 \\
\hline USA_ESP_CORR & -0.036 & USA_ESP_CORR & 0.078 & USA_ESP_CORR & -0.134 \\
\hline
\end{tabular}




\begin{tabular}{|c|c|c|c|}
\hline & $\ln L_{G A R C H(1,1)}$ & $\ln L_{M S-G A R C H(1,1)}$ & Test LR \\
\hline FRA & -2704.54 & -2682.98 & $43.12^{+++}$ \\
\hline GBR & -2392.33 & -2374.68 & $35.3^{+++}$ \\
\hline JPN & -2975.05 & -2.945 .44 & $59.22^{+++}$ \\
\hline NLD & -2631.19 & -2608.4 & $45.58^{+++}$ \\
\hline ESP & -2602.79 & -2565.92 & - \\
\hline AUS & -2250.66 & -2221.42 & - \\
\hline IRL & -2896.1 & -2828.07 & - \\
\hline DNK & -2682.07 & -2642.71 & $73.74^{+++}$ \\
\hline NOR & -3008.62 & -2978.3 & $58.48^{+++}$ \\
\hline SWE & -2709.68 & -2663.62 & $136.1^{+++}$ \\
\hline CHE & -2342.38 & -2314.83 & $55.1^{+++}$ \\
\hline USA & -1393.1 & -1369.58 & $47.04^{+++}$ \\
\hline
\end{tabular}

Note: +++ indicate the null hypothesis of no regime switching volatility is rejected at the $1 \%$ level.

Table 5: MS-GARCH Results

\begin{tabular}{|c|c|c|c|c|c|c|c|}
\hline & France & GBR & Japan & Netherlands & Spain & Australia & Ireland \\
\hline \multirow[t]{2}{*}{$\mu\left(S_{t}=1\right)$} & $-0.371 * * *$ & $-0.307 * * *$ & $-0.341 * * *$ & $-0.376^{* * *}$ & $-0.584 * * *$ & $-0.491 * * *$ & $-0.427 * * *$ \\
\hline & $(-0.0254)$ & $(-0.0271)$ & $(-0.0085)$ & $(-0.0301)$ & $(-0.0416)$ & $(-0.031)$ & $(-0.0248)$ \\
\hline \multirow{2}{*}{$\mu\left(S_{t}=2\right)$} & $0.099 * * *$ & $0.085^{* * *}$ & $0.069 * * *$ & $0.097 * * *$ & $0.134 * * *$ & $0.140 * *$ & $0.119 * * *$ \\
\hline & $(-0.029)$ & $(-0.0226)$ & $(-0.0199)$ & $(-0.0325)$ & $(-0.0534)$ & $(-0.0708)$ & $(-0.0451)$ \\
\hline \multirow[t]{2}{*}{$\theta_{1}$} & $-0.082 * * *$ & $-0.084 * * *$ & $-0.039 * * *$ & $-0.023 * * *$ & $-0.053 * * *$ & $0.099 * * *$ & - \\
\hline & $(-0.0303)$ & $(-0.0263)$ & $(-0.0165)$ & $(-0.0088)$ & $(-0.0182)$ & $(-0.0383)$ & - \\
\hline \multirow[t]{2}{*}{$w\left(S_{t}=1\right)$} & $0.393 * * *$ & $0.312^{* * *}$ & $0.744 * * *$ & $0.361 * * *$ & $0.363 * * *$ & $0.175^{* * *}$ & $0.463 * * *$ \\
\hline & $(-0.0247)$ & $(-0.0234)$ & $(-0.0194)$ & $(-0.0301)$ & $(-0.039)$ & $(-0.0273)$ & $(-0.0557)$ \\
\hline \multirow[t]{2}{*}{$w\left(S_{t}=2\right)$} & $0.099 * * *$ & $0.085 * * *$ & $0.125^{* * *}$ & $0.089 * * *$ & $0.088 * *$ & $0.056 * *$ & $0.085^{* *}$ \\
\hline & $(-0.029)$ & $(-0.0226)$ & $(-0.0304)$ & $(-0.0329)$ & $(-0.0404)$ & $(-0.0258)$ & $(-0.0377)$ \\
\hline \multirow[t]{2}{*}{$\alpha$} & $0.053^{* *}$ & $0.061 * * *$ & $0.059 * *$ & $0.050 * *$ & $0.094 * * *$ & $0.089 * *$ & $0.047 * *$ \\
\hline & $(-0.0253)$ & $(-0.0174)$ & $(-0.0246)$ & $(-0.0216)$ & $(-0.0329)$ & $(-0.0372)$ & $(-0.019)$ \\
\hline \multirow[t]{2}{*}{$\beta$} & $0.928 * * *$ & $0.919 * * *$ & $0.923 * * *$ & $0.931 * * *$ & $0.886 * * *$ & $0.893 * *$ & $0.931 * * *$ \\
\hline & $(-0.3504)$ & $(-0.2458)$ & $(-0.308)$ & $(-0.3122)$ & $(-0.3374)$ & $(-0.3529)$ & $(-0.3072)$ \\
\hline $\mathbf{P}_{11}$ & 0.905 & 0.909 & 0.783 & 0.913 & 0.747 & 0.709 & 0.901 \\
\hline $\mathbf{P}_{22}$ & 0.985 & 0.982 & 0.987 & 0.984 & 0.964 & 0.947 & 0.975 \\
\hline$d_{1}$ & 10.53 & 10.98 & 4.61 & 11.49 & 3.95 & 3.44 & 10.10 \\
\hline$d_{2}$ & 66.66 & 55.55 & 76.92 & 62.5 & 27.78 & 18.87 & 40 \\
\hline $\mathbf{L}$ & -2682.98 & -2374.68 & -2945.44 & -2608.4 & -2565.92 & -2221.42 & -2828.07 \\
\hline \multirow[t]{2}{*}{$\mathbf{Q}(\mathbf{1 2})$} & 15.79 & 9.33 & 8.30 & 8.87 & 8.97 & 9.36 & 10.15 \\
\hline & [0.149] & [0.591] & [0.686] & [0.634] & [0.624] & [0.882] & [0.517] \\
\hline \multirow[t]{2}{*}{$Q^{2}(12)$} & 17.80 & 21.66 & 26.76 & 16.67 & 14.98 & 7.86 & 27.14 \\
\hline & [0.122] & [0.041] & [0.008] & [0.162] & [0.243] & [0.796] & {$[0.007]$} \\
\hline
\end{tabular}




\begin{tabular}{|c|c|c|c|c|c|}
\hline & Denmark & Norway & Sweden & Switzerland & USA \\
\hline \multirow[t]{2}{*}{$\mu\left(S_{t}=1\right)$} & $-0.481 * * *$ & $-0.647 * * *$ & $-0.639 * * *$ & $-0.357 * * *$ & $0.1827 * * *$ \\
\hline & $(-0.0314)$ & $(-0.0364)$ & $(-0.0262)$ & $(-0.0358)$ & $(0.01732)$ \\
\hline \multirow[t]{2}{*}{$\mu\left(S_{t}=2\right)$} & $0.137 * *$ & $0.244 * * *$ & $0.187^{* *}$ & $0.091 *$ & $-0.9832 * * *$ \\
\hline & $(0.0582)$ & $(0.0673)$ & $(0.0751)$ & $(0.0471)$ & $(-0.01483)$ \\
\hline \multirow[t]{2}{*}{$\theta_{1}$} & $-0.018 * *$ & $-0.048 * * *$ & $-0.087 * *$ & $-0.043 * *$ & $-0.133 * * *$ \\
\hline & $(-0.0073)$ & $(-0.0186)$ & $(-0.0352)$ & $(-0.0171)$ & $(-0.02637)$ \\
\hline \multirow[t]{2}{*}{$w\left(S_{t}=1\right)$} & $0.530 * * *$ & $0.438 * * *$ & $0.270 * * *$ & $0.369 * * *$ & $0.6128 * * *$ \\
\hline & $(-0.0573)$ & $(-0.0566)$ & $(-0.0412)$ & $(0.0579)$ & $(-0.04444)$ \\
\hline \multirow[t]{2}{*}{$w\left(S_{t}=2\right)$} & $0.145 * * *$ & $0.141 * * *$ & $0.057 * * *$ & $0.113 * *$ & $2.550 * * *$ \\
\hline & $(-0.0537)$ & $(-0.0461)$ & $(-0.0093)$ & $(-0.0480)$ & $(-0.02823)$ \\
\hline \multirow[t]{2}{*}{$\alpha$} & $0.074 *$ & $0.082 * * *$ & $0.067 * * *$ & $0.067 * * *$ & $0.1029 * * *$ \\
\hline & $(-0.0466)$ & $(-0.0358)$ & $(-0.0212)$ & $(-0.0326)$ & $(-0.03312)$ \\
\hline \multirow[t]{2}{*}{$\beta$} & $0.886^{* *}$ & $0.885^{* * *}$ & $0.914 * * *$ & $0.901 * * *$ & $0.808^{* * *}$ \\
\hline & $(-0.3725)$ & $(-0.3329)$ & $(-0.2268)$ & $(-0.3412)$ & $(-0.13403)$ \\
\hline $\mathbf{P}_{11}$ & 0.848 & 0.746 & 0.680 & 0.897 & 0.9756 \\
\hline $\mathbf{P}_{22}$ & 0.975 & 0.948 & 0.939 & 0.981 & 0.8875 \\
\hline$d_{1}$ & 6.58 & 3.94 & 3.12 & 9.71 & 40.98 \\
\hline$d_{2}$ & 40 & 19.23 & 16.39 & 52.63 & 8.88 \\
\hline $\mathbf{L}$ & -2642.71 & -2978.3 & -2663.62 & -2314.83 & -1369.58 \\
\hline \multirow[t]{2}{*}{$Q(12)$} & 18.88 & 14.83 & 13.16 & 20.98 & 20.252 \\
\hline & {$[0.063]$} & [0.191] & {$[0.283]$} & {$[0.034]$} & {$[0.062]$} \\
\hline \multirow[t]{2}{*}{$Q^{2}(12)$} & 33.62 & 18.81 & 21.61 & 18.82 & 12.969 \\
\hline & [0.001] & [0.093] & [0.042] & [0.093] & {$[0.371]$} \\
\hline
\end{tabular}

Note: standard deviations are reported in parentheses. *, ** and *** indicate that coefficients are significant at the $10 \%, 5 \%$ and $1 \%$ levels respectively. 
Graph 1: Market Index Returns

R_AUS

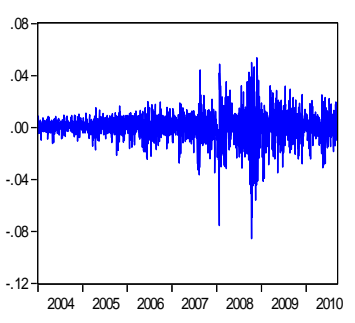

R_FRA

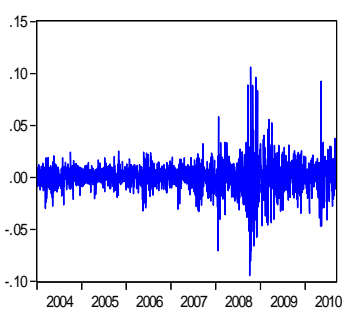

R_NLD

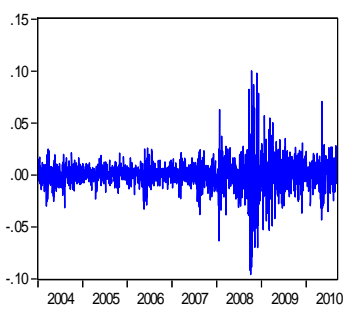

R_CHE

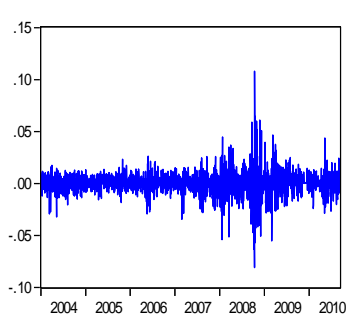

R_GBR

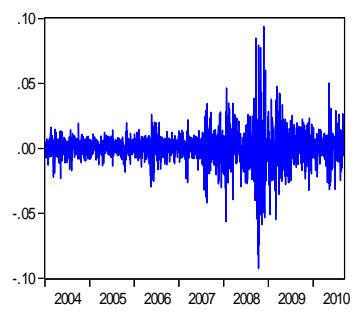

R_NOR

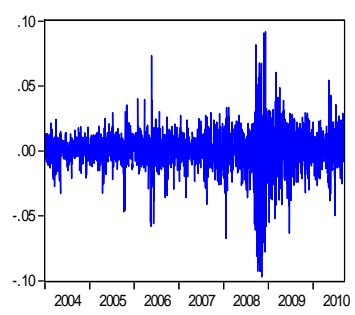

R_DNK

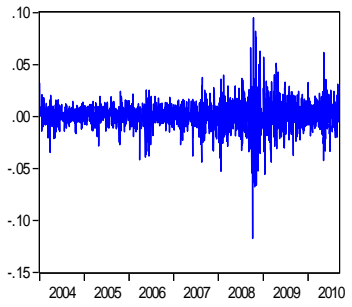

R_IRL

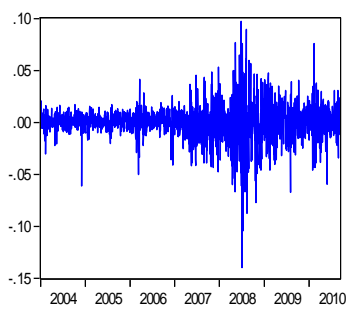

R_SWE

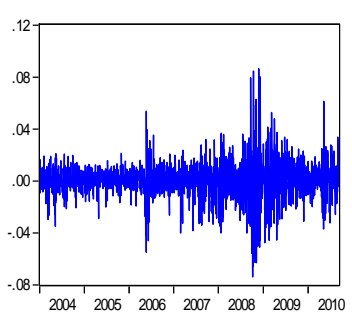

R_ESP

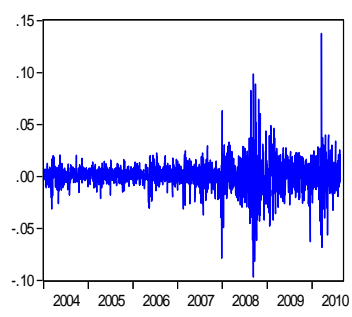

R_JPN

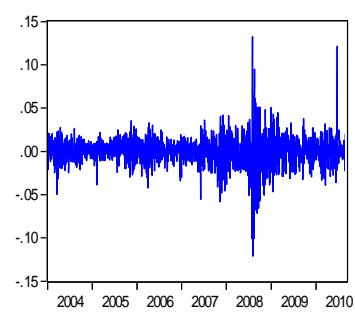

R_USA

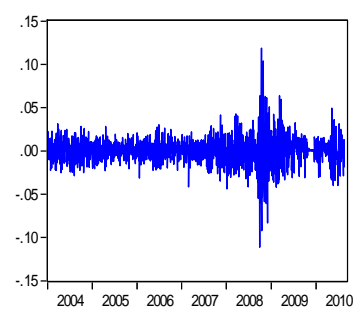


Graph 2: Market Index Dynamic Correlations

US_AUS_CORR

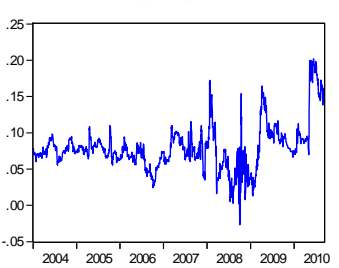

US_FRA_CORR

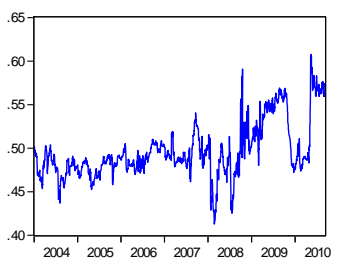

US_NLD_CORR

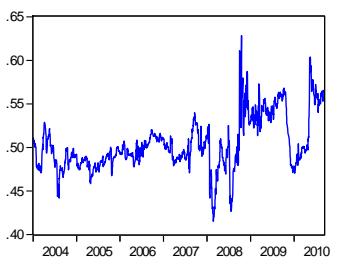

US_CHE_CORR

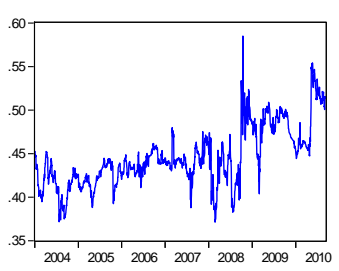

US_GBR_CORR

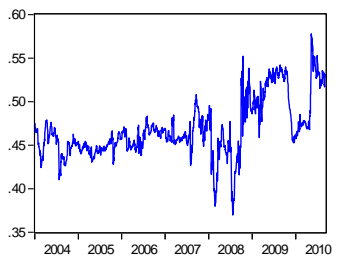

US_NOR_CORR

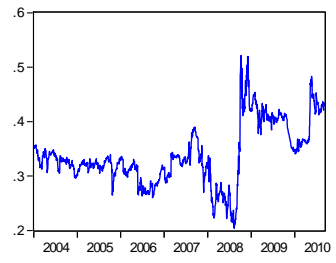

US_DNK_CORR

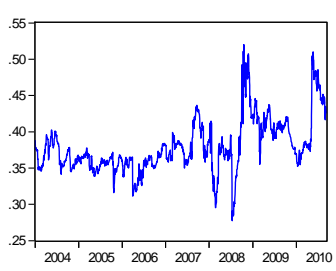

US_IRL_CORR

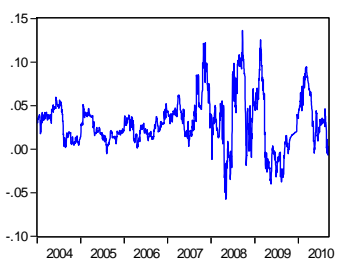

US_SWE_CORR

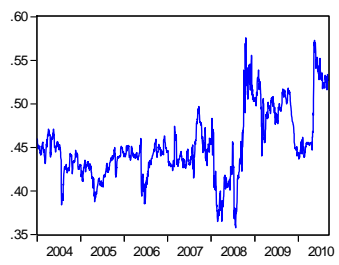

US ESP CORR

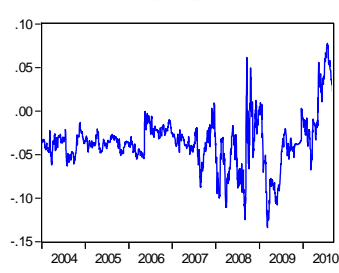

US_JPN_CORR

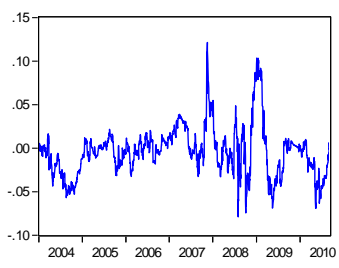

Graph 3: Market Index Volatility
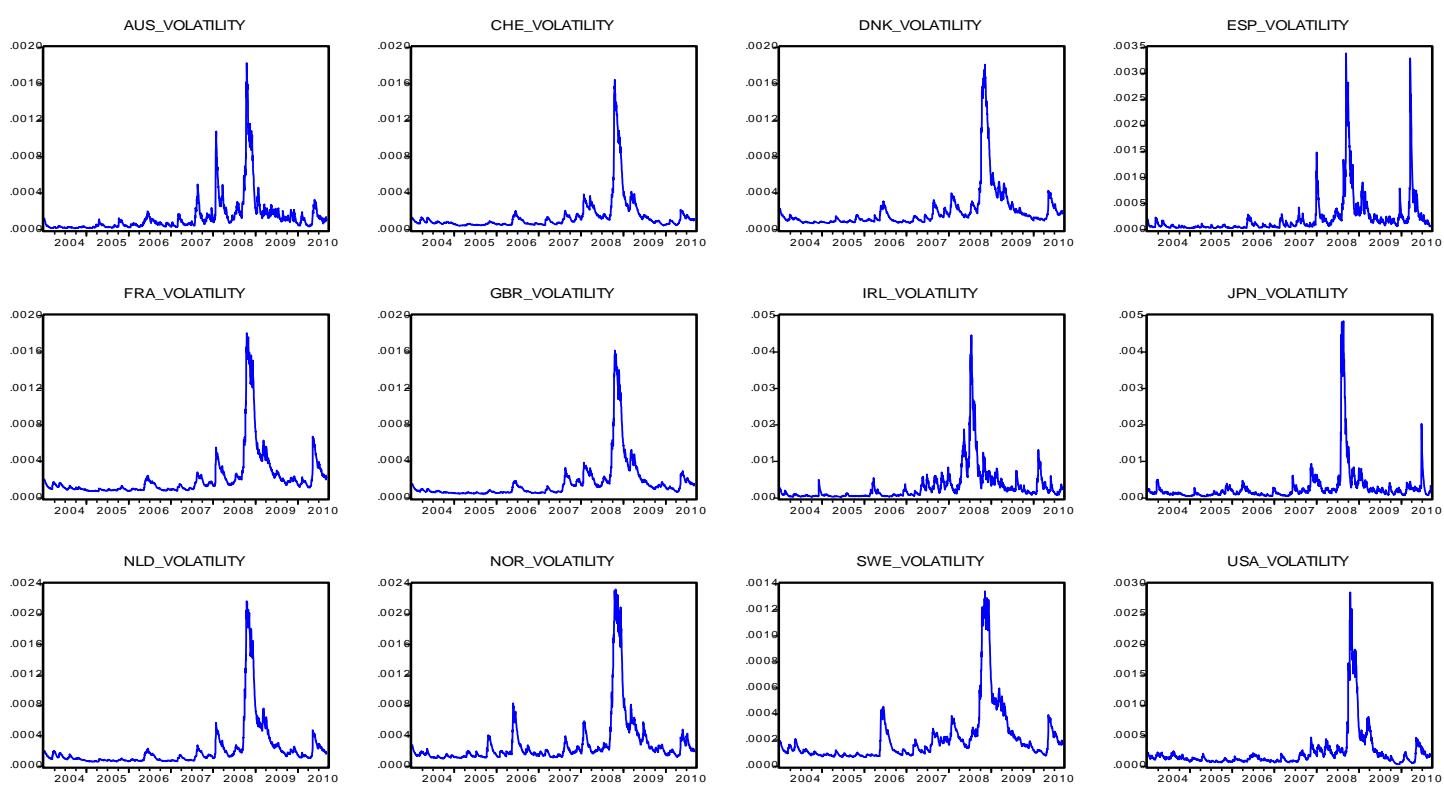

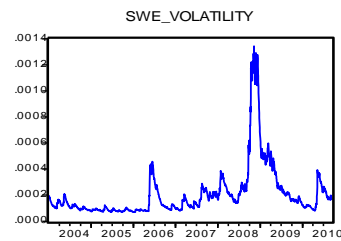

USA VOLATILITY

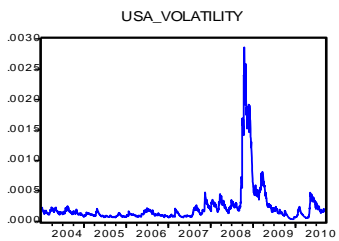


Graph 4: Regime Switching Volatility Under High Mean Low Volatility

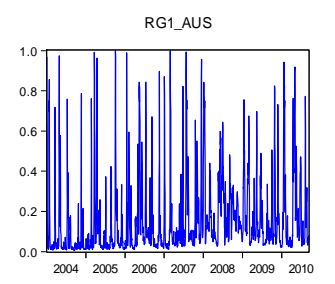

RG1_FRA

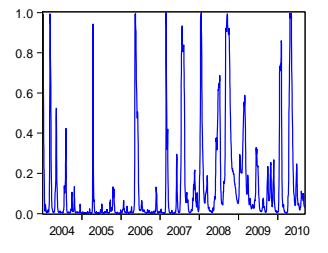

RG1_JPN

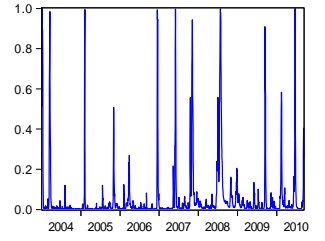

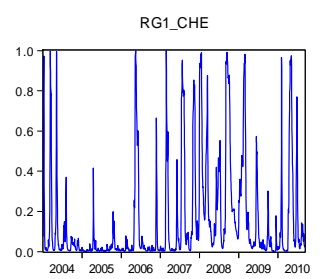

RG1_GBR

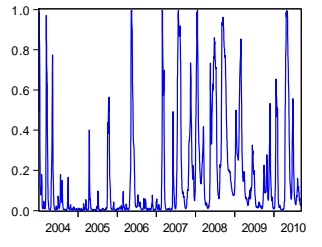

RG1_NLD

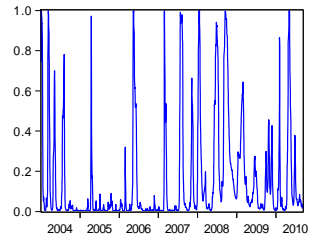

RG1 DNK

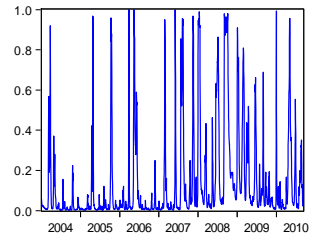

RG1_IRL

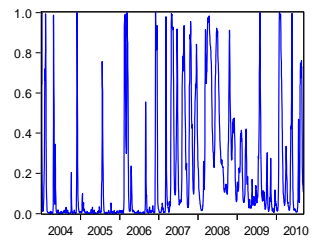

RG1_NOR

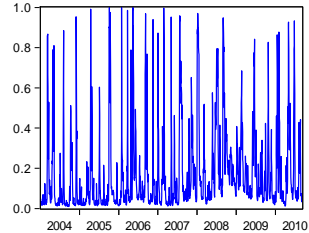

RG1_ESP

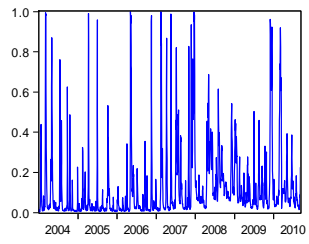

RG1_TA

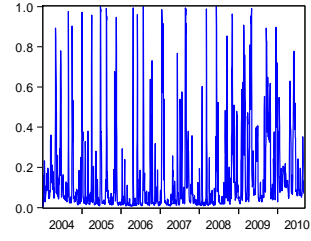

RG1_SWE

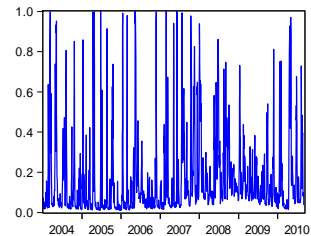

Graph 5: Regime Switching Volatility Under Low Mean High Volatility

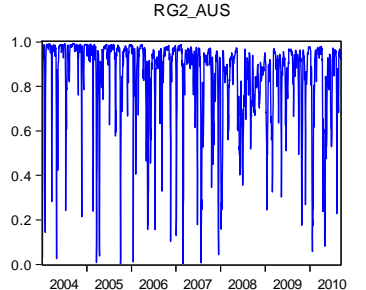

RG2_FRA

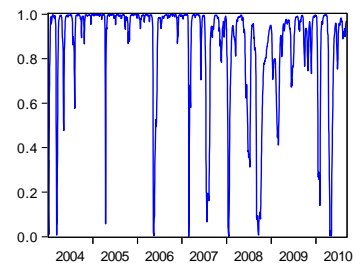

RG2_JPN

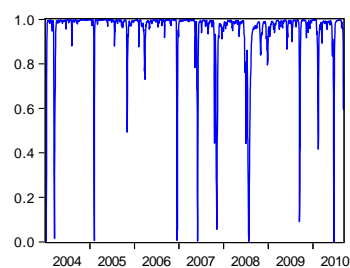

RG2_CHE

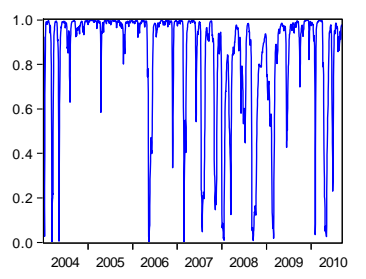

RG2_GBR

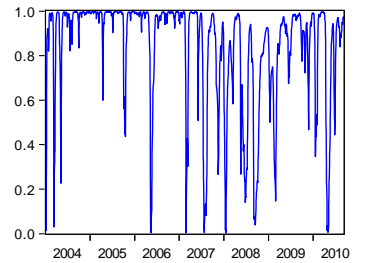

RG2_NLD

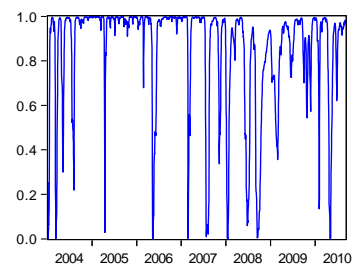

RG2_DNK

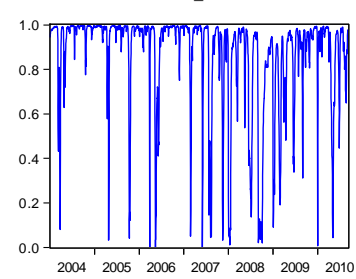

RG2_IRL

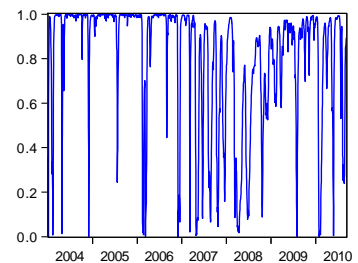

RG2_NOR

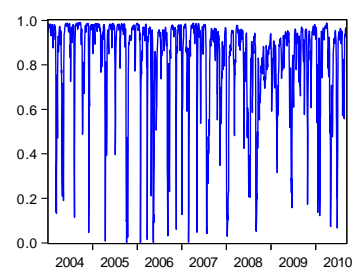

RG2_ESP

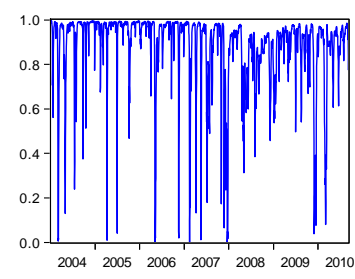

RG2_ITA

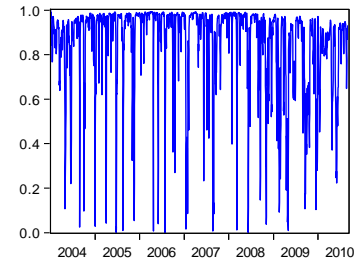

RG2_SWE

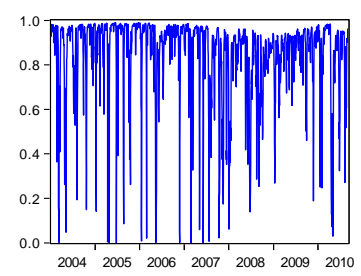


NOTES 